\title{
Recovery of Delayed Graft Function after Calcineurin Inhibitor Sparing Regimen in a Renal Transplant Patient with Calcineurin Inhibitor Toxicity: A Case Report
}

\author{
Division of Nephrology, Department of Internal Medicine ${ }^{1}$, Division of Vascular and Endovascular Surgery, \\ Department of Surgery², Yeungnam University Medical Center, Yeungnam University College of Medicine, Daegu, Korea \\ Seok Hui Kang, M.D. ${ }^{1}$, Woo Sung Yun, M.D. ${ }^{2}$, Kyu Hyang Cho, M.D. ${ }^{1}$, Jun Young Do, M.D. ${ }^{1}$, \\ Kyung Woo Yoon, M.D. ${ }^{1}$ and Jong Won Park, M.D. ${ }^{1}$
}

The recipient candidate was a 51-year-old male with end-stage renal disease owing to diabetes mellitus. The initial immunosuppressive regimen included basiliximab for induction and tacrolimus, mycophenolate mofetil, and steroids. Urine output was $413 \mathrm{~mL} /$ day on the operative day and $100 \mathrm{~mL} /$ day on the postoperative day (POD) 1 . There was no definite stenosis of the ureter or vessels. He had anuria on POD 2 4 and he had undergone hemodialysis. His serum creatinine level did not decrease. Therefore, a graft biopsy was performed on POD 4. The pathologic finding was consistent with acute calcineurin inhibitor (CNI) toxicity. There was no evidence of rejection or acute tubular necrosis. Anuria continued on POD 6; therefore, we started sirolimus instead of a CNI based regimen. Graft function was gradually recovered 1 day after reduction of CNI dose and hemodialysis was stopped. The serum creatinine level was normalized on POD 10. He was discharged on POD 21.

Key Words: Calcineurin inhibitor, Sirolimus, Delayed graft function, Kidney transplantation 중심 단어: 칼시뉴린 억제제, 실로리무스, 지연성 이식신 기능장애, 신장이식

\section{INTRODUCTION}

Use of calcineurin inhibitors (CNI) such as cyclosporine and tacrolimus has resulted in improved graft survival following renal transplantation(1,2). However, they are associated with acute or chronic nephrotoxicity. Since approval by the Food and Drug Administration in 1999 for use in transplantation, sirolimus has been reported to be less nephrotoxic than $\mathrm{CNIs}(3,4)$. Therefore, sirolimus combined with low dose of CNI can result in recovery of DGF by CNI tox-

Received December 31, 2013

Revised July 17, 2014

Accepted August 29, 2014

Corresponding author: Jong Won Park

Division of Nephrology, Department of Internal Medicine, Yeungnam University Medical Center, Yeungnam University College of Medicine, 170 Hyeonchung-ro, Nam-gu, Daegu 705-717, Korea

Tel: 82-53-680-3849, Fax: 82-53-654-8386

E-mail: jwpark@med.yu.ac.kr icity or may be useful for patients at risk for development of DGF by CNI toxicity. Here, we report a case of successful recovery from CNI toxicity after sirolimus combined with low dose of $\mathrm{CNI}$ in a renal transplant recipient with DGF.

\section{CASE REPORT}

The donor was a 51-year-old male who succumbed to an intracranial hemorrhage. He had no known underlying renal or systemic disease and the serum creatinine level at the time of organ harvest was $0.98 \mathrm{mg} / \mathrm{dL}$. The recipient candidate was a 51-year-old male with end-stage renal disease owing to diabetes mellitus who had received peritoneal dialysis for 6 years. He had transferred to hemodialysis and maintained hemodialysis for 2 years. The blood types of the donor and the recipient were compatible as $\mathrm{A}^{+}$. The human 
leukocyte antigen mismatch was 4/6; however, pretransplant $\mathrm{T}$ - and B-lymphocyte crossmatches were negative. Cold ischemic time was 50 minutes. Initial immunosuppressive regimen included basiliximab for induction and tacrolimus, mycophenolate mofetil (MMF), and steroids as maintenance therapy. Cold ischemic time was 50 minutes. No hypotensive events or complications were noted.

Urine output was $413 \mathrm{~mL} /$ day on the operative day and $100 \mathrm{~mL} /$ day on postoperative day (POD) 1 (Fig. 1). On POD 1, duplex ultrasonography showed 0.85 for resistance index. No definite stenosis of ureter or vessels was observed. He had oliguria on POD1 and anuria until POD 2 4. He had received hemodialysis. His serum creatinine level did not decrease. Therefore, a graft biopsy was performed on POD 4. The pathologic finding was consistent with acute $\mathrm{CNI}$ toxicity and arterial nephrosclerosis of the donor kidney (Fig. 2A C). Tacrolimus level was $15.3 \mathrm{ng} / \mathrm{mL}$. No evidence of rejection or acute tubular necrosis was observed.

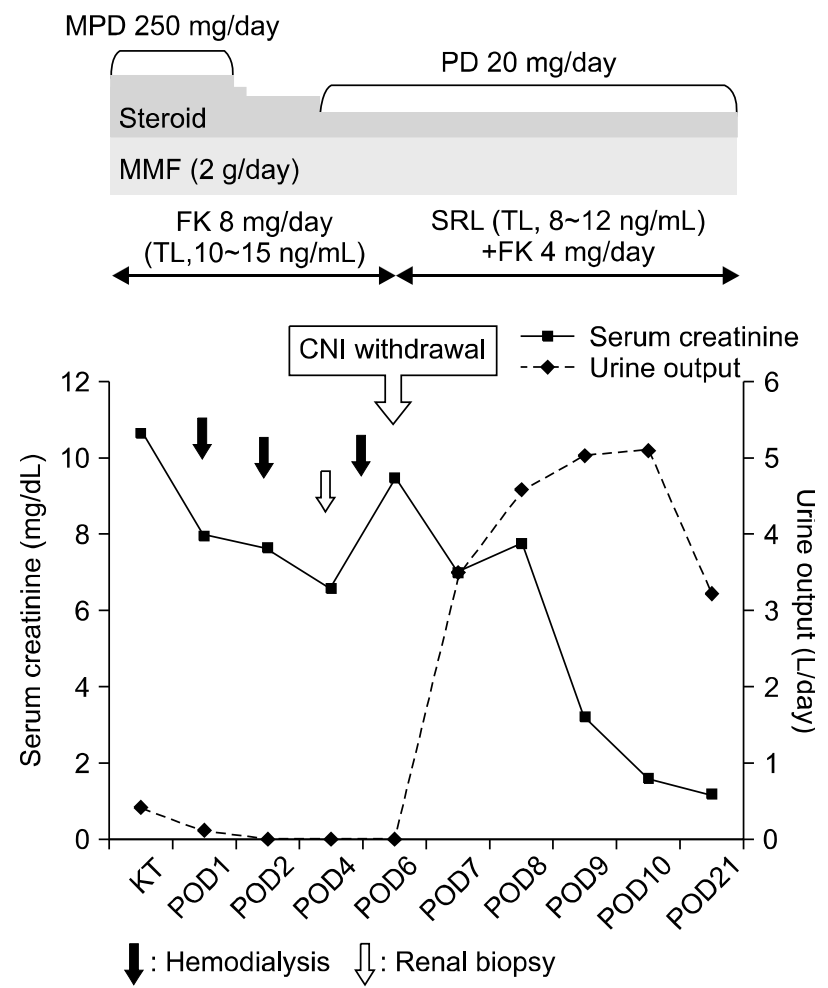

Fig. 1. Course of urine output and serum creainine levels according to treatment. Abbreviations: KT, kidney transplantation; POD, postoperative day; CNI, calcineurin inhibitor; MPD, methylprednisolone; PD, prednisolone; MMF, mycophenolate mofetil; $\mathrm{FK}$, tacrolimus; TL, trough level; SRL, sirolimus.
He was not treated with intravenous hyperosmotic fluid, radiocontrast agent, or immunoglobulin.

Anuria continued on POD 6; therefore, we planned a CNI withdrawal regimen. Sirolimus was initiated with a loading dose of $4 \mathrm{mg} /$ day, followed by $2 \mathrm{mg}$ /day once daily, aiming for an initial target trough level of 8 to $12 \mathrm{ng} / \mathrm{mL}$. At this time, tacrolimus was reduced by $50 \%$, from 8 to $4 \mathrm{mg} /$ day. MMF (2 g/day) and steroid (20 mg/day) were maintained. Graft function was gradually recovered one day after reduction of CNI dose by $50 \%$ and hemodialysis was stopped. The serum creatinine level was normalized on POD 10. On POD 11, follow-up duplex sonography showed 0.76 for resistance index. He was discharged on POD 21. On POD 47, a graft biopsy was performed repeatedly. Compared to initial finding, the acute CNI toxicity showed improvement (Fig. 2D). Tacrolimus and silorimus levels were 6.2 and 9 $\mathrm{ng} / \mathrm{mL}$, respectively. On POD 55, the patient remained asymptomatic under maintenance therapy with prednisolone $20 \mathrm{mg} /$ day, sirolimus $2 \mathrm{mg} / \mathrm{day}, \mathrm{MMF} 2 \mathrm{~g} / \mathrm{day}$, and tacrolimus $4 \mathrm{mg} /$ day, and the serum creatinine was $1.11 \mathrm{mg} / \mathrm{dL}$. Urine dip stick test was negative for protein. Tacrolimus was tapered at POD. The patient is currently on three-drug immunosuppressive regimen (prednisolone, sirolimus, and $\mathrm{MMF})$.

\section{DISCUSSION}

CNIs have been the cornerstone of immunosuppression in kidney transplantation since the late 1970s. Although CNI have been effective in reducing the incidence of rejection and improving graft survival, CNIs per se have been associated with development of acute and chronic nephrotoxicity(5). CNI nephrotoxicity is divided into arteriolopathy and tubulopathy. Isometric tubular epithelial cell vacuolization is commonly seen in graft biopsy of acute CNI nephrotoxicity; however, arteriolopathy is the main cause of graft dysfunction after kidney transplantation. Arteriolopathy by $\mathrm{CNI}$ is associated with an increase in vasoconstrictor, decrease in vasodilator, and activation of the renin-angiotensin system, consequently resulting in an increase in vascular resistance and a decrease in glomerular filtration rate(5). In addition, their prolonged use can lead to chronic allograft nephropathy and graft loss. The mammalian target 

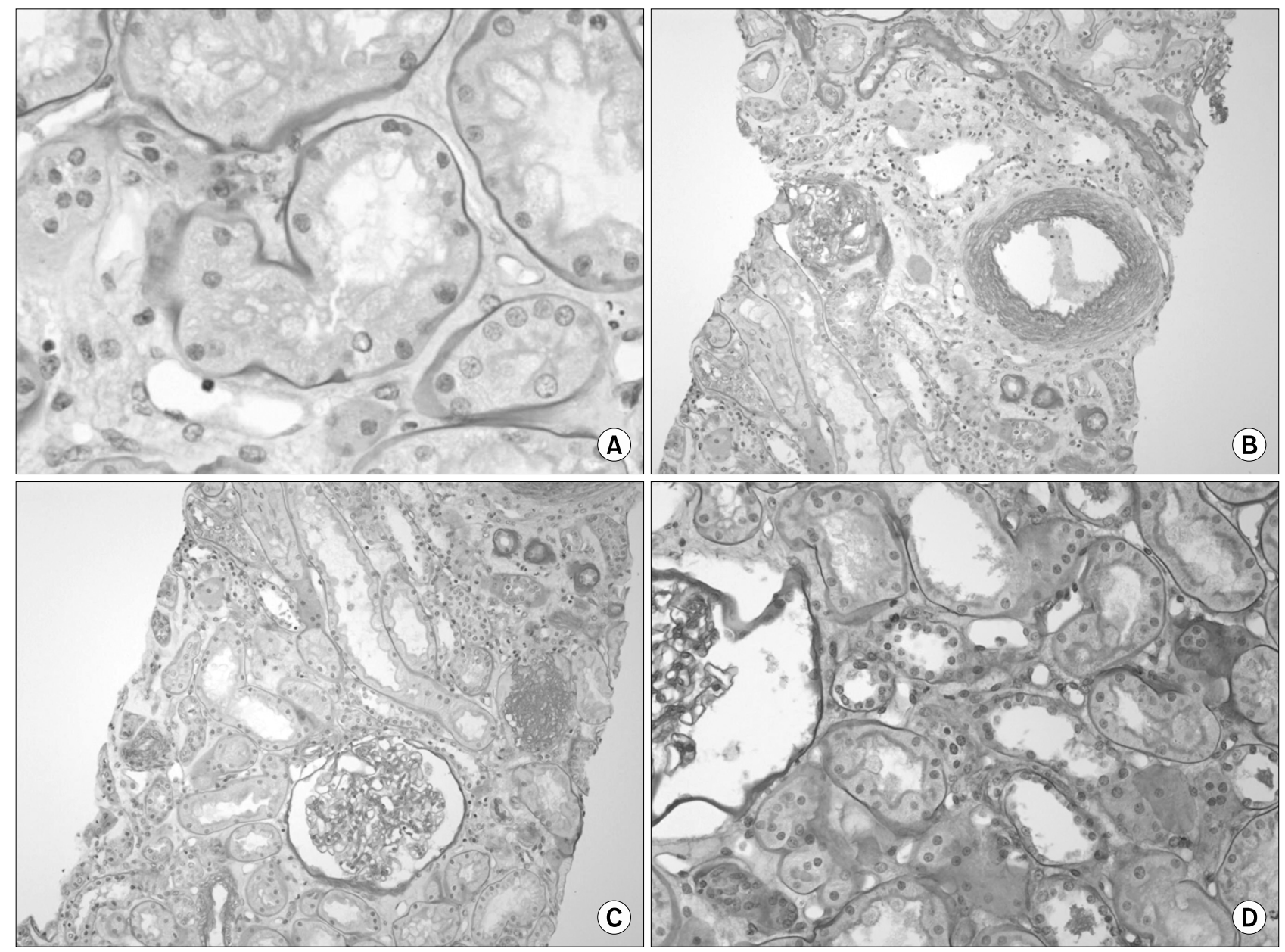

Fig. 2. $(\mathrm{A} \sim \mathrm{C})$ Initial light microscopy shows acute calcineurin inhibitor toxicity; this finding showed improvement at follow-up biopsy (D) (HE stain, $\times 800$ for $\mathrm{A}$ and $\mathrm{D}$; $\times 400$ for $\mathrm{B}$ and $\mathrm{C}$ ).

of rapamycin inhibitor has received increasing attention as an alternative immunosuppressant for decreasing CNI nephrotoxicity $(3,4,6)$. CNI minimization, avoidance, withdrawal, or conversion regimens were introduced. Many clinical studies demonstrated the efficacy of CNI sparing regimens maintained good renal function with an acceptable level of safety(7-13).

$\mathrm{CNI}$ nephrotoxicity may be exacerbated in recipients with pre-existing donor pathology, such as diabetes, hypertension, or ischemic injuries resulting in delayed graft function (DGF)(6). In our case, there was an increase in resistance index of renal vessels, but no definite stenosis of vessels. Clinical findings revealed DGF and graft biopsy showed evidence of acute CNI nephrotoxicity and pre-existing hypertensive renal disease of the donor kidney. There was no evi- dence of acute tubular necrosis and rejection. These findings indicate that DGF is caused by CNI nephrotoxicity. We think that ischemia by afferent arteriolar vasoconstriction combined with pre-existing hypertensive nephropathy play an important role in development of DGF. However, McTaggart et al.(14) reported that de novo sirolimus prolonged recovery from DGF after kidney transplantation. For patients with DGF by CNI toxicity without other cause, CNI withdrawal combined with sirolimus will lead to a decrease in renal vascular resistance and recovery of DGF.

In conclusion, our case suggests that recovery of DGF by CNI without other causes can be achieved using a CNI sparing regimen. However, accumulation of a larger number of cases of a similar nature may be required before a definite consensus can be reached. 


\section{REFERENCES}

1) Calne RY, White DJ, Thiru S, Evans DB, McMaster P, Dunn DC, et al. Cyclosporin A in patients receiving renal allografts from cadaver donors. Lancet 1978;2:1323-7.

2) Calne RY, Rolles K, White DJ, Thiru S, Evans DB, McMaster $\mathrm{P}$, et al. Cyclosporin A initially as the only immunosuppressant in 34 recipients of cadaveric organs: 32 kidneys, 2 pancreases, and 2 livers. Lancet 1979;2:1033-6.

3) Morales JM, Wramner L, Kreis H, Durand D, Campistol JM, Andres A, et al. Sirolimus does not exhibit nephrotoxicity compared to cyclosporine in renal transplant recipients. Am J Transplant 2002;2:436-42.

4) Flechner SM, Kurian SM, Solez K, Cook DJ, Burke JT, Rollin $\mathrm{H}$, et al. De novo kidney transplantation without use of calcineurin inhibitors preserves renal structure and function at two years. Am J Transplant 2004;4:1776-85.

5) Naesens M, Kuypers DR, Sarwal M. Calcineurin inhibitor nephrotoxicity. Clin J Am Soc Nephrol 2009;4:481-508.

6) Shaffer D, Langone A, Nylander WA, Goral S, Kizilisik AT, Helderman JH. A pilot protocol of a calcineurin-inhibitor free regimen for kidney transplant recipients of marginal donor kidneys or with delayed graft function. Clin Transplant 2003;17 Suppl 9:31-4.

7) Pascual M, Curtis J, Delmonico FL, Farrell ML, Williams WW Jr, Kalil R, et al. A prospective, randomized clinical trial of cyclosporine reduction in stable patients greater than 12 months after renal transplantation. Transplantation 2003;75:1501-5.

8) Ciancio G, Burke GW, Gaynor JJ, Mattiazzi A, Roth D, Kupin $\mathrm{W}$, et al. A randomized long-term trial of tacrolimus/siroli- mus versus tacrolimus/mycophenolate mofetil versus cyclosporine (NEORAL)/sirolimus in renal transplantation. II. Survival, function, and protocol compliance at 1 year. Transplantation 2004;77:252-8.

9) Groth CG, Bäckman L, Morales JM, Calne R, Kreis H, Lang $\mathrm{P}$, et al. Sirolimus (rapamycin)-based therapy in human renal transplantation: similar efficacy and different toxicity compared with cyclosporine. Sirolimus European Renal Transplant Study Group. Transplantation 1999;67:1036-42.

10) Johnson RW, Kreis H, Oberbauer R, Brattström C, Claesson K, Eris J. Sirolimus allows early cyclosporine withdrawal in renal transplantation resulting in improved renal function and lower blood pressure. Transplantation 2001;72:777-86.

11) Gonwa TA, Hricik DE, Brinker K, Grinyo JM, Schena FP; Sirolimus Renal Function Study Group. Improved renal function in sirolimus-treated renal transplant patients after early cyclosporine elimination. Transplantation 2002;74: 1560-7.

12) Schena FP, Pascoe MD, Alberu J, del Carmen Rial M, Oberbauer R, Brennan DC, et al. Conversion from calcineurin inhibitors to sirolimus maintenance therapy in renal allograft recipients: 24-month efficacy and safety results from the CONVERT trial. Transplantation 2009;87:233-42.

13) Weir MR, Mulgaonkar S, Chan L, Shidban H, Waid TH, Preston D, et al. Mycophenolate mofetil-based immunosuppression with sirolimus in renal transplantation: a randomized, controlled Spare-the-Nephron trial. Kidney Int 2011;79:897-907.

14) McTaggart RA, Gottlieb D, Brooks J, Bacchetti P, Roberts JP, Tomlanovich S, et al. Sirolimus prolongs recovery from delayed graft function after cadaveric renal transplantation. Am J Transplant 2003;3:416-23. 